\title{
Perancangan Immobilizer Berbasis RFID untuk Sepeda Motor
}

\author{
Heru Supriyono \\ Jurusan Teknik Elektro Universitas Muhammadiyah Surakarta (UMS) \\ Surakarta, Indonesia Heru.Supriyono@ums.ac.id \\ Ardhya Dwi Nor Setyawan \\ Jurusan Informatika Universitas Muhammadiyah Surakarta (UMS) \\ Surakarta, Indonesia Ardhyadwi919@gmail.com
}

\begin{abstract}
Abstraksi - Seiring majunya perkembangan teknologi bidang otomotif dan berkembangnya produksi kendaraan bermotor muncul masalah kriminalitas khususnya tindak pencurian kendaraan motor kejahatan serta sistem keamanan pada kendaraan itu sendiri yang masih lemah serta rawan penggunaan kunci ganda $\mathrm{T}$ yang digunakan dalam merusak rumah kunci sepeda motor. Pada penelitian ini penulis membuat inovasi dengan menggunakan metode eskperimental membuat sistem keamanan bermotor berbasis RFID dengan menggunakan Arduino UNO sebagai mikrokontroler serta buzzer berfungsi sebagai alarm peringatan, fungsi RFID itu sendiri untuk mencegah hubungan listrik yang berasal dari aki menuju koil sehingga motor tidak bisa dihidupkan tanpa RFID ID tag dari pemilik bermotor sehingga motor aman dari tindak kejahatan pencurian dan jarak efisien yang disarankan dalam penggunaan RFID 0 hingga $2 \mathrm{~cm}$ serta menggunakan sensor getar untuk meminimalisir dalam pencurian sepeda motor
\end{abstract}

\section{Katakunci-arduino, keamanan, mikrokontroler, RFID, tag}

\section{Pendahuluan (Heading 1$)$}

Seiring majunya perkembanganteknologi masakini baik dalam teknologi inforasi maupun dibidang lain seperti dibidang otomotif telah memudahkan kegiatan manusia. Awalnya kegiatan manusia berpindah tempat secara berjalan kaki atau menggunakan tenaga hewan kini telah bergeser menggunakan kendaraan bermotor seperti motor dan mobil. Indonesia merupakansalah satu negara pengguna kendaraan bermotor yang terbanyak. Berdasarkan data Asosiasi Industri Sepeda Motor pada tahun 2015 sebanyak 6,5 Juta unit dan pada tahun 2014 sebanyak 7,7 Juta unit kendaraan bermotor[1]. Banyaknya kendaraan bermotor berdampak dengan semakin tingginya kasus pencurian kendaraan bermotor. Berdasarkan data yang dimiliki Polda Jateng dan Polrestabes Semarang kasus pencurian kendaraan bermotor sebanyak 186 kasus pada tahun 2015 [2] dan pada tahun 2017 angka kasus pencurian meningkat 328 kasus [3]
Banyaknya pencurian kendaraan bermotor disebabkan karena kelengahan pemilik kendaraan bermotor dalam mengawasi kendaraannya dan faktor lainnya lingkungan yang rawan akan tindak kejahatan pencurian kendaraan bermotor. Selain itu sistem keamanan kendaraan bermotor konvensional sendiri yang masih sangat lemah. Sebagai contoh hanya dengan kunci letter $\mathrm{T}$ pencuri dapat dengan mudah membobol kunci kendaraan bermotor.

Dengan adanya permasalahan diatas maka perlu ditingkatkanya sistem keamanan pada kendaraan bermotor. Salah satu sistem keamanana yang tepat yaitu Immobilizer berbasis Radio Frequency Indentification (RFID). Sistem ini merupakan sistem keamanan dengan memadukan antara kunci konvensional dengan RFID

Sistem start pada motor yaitu ketika kunci di putar posisi on maka listrik yang berasal dari aki akan mengalir menuju koil pada dynamo dan tombol start ditekan untuk menghasilkan 
listrik dan bunga api yang diteruskan pada koil sehingga dynamo berkerja untuk menghidupakn mesin sekaligus mengisi daya pada aki kering dan penelitian ini mencegah hubungan listrik antara starter dengan koil menggunakan teknologi RFID

\section{DASAR TEORI DAN TINJAUAN PUSTAKA}

RFID sebuah sistem non-kontak nirkabel yang menggunakan gelombang electromagnetic frekuensi radio untuk mentransfer data dari tag yang dilampirkan ke sebuah objek, untuk identifikasi dan pelacakan otormatis [4]. Komponen RFID terdiri dari RFID tag dan RFID reader. RFID tag adah sebuah tag yang didalamnya terdapat magnetik koil yang diggunakan untuk menghasilkan gelombang frekuensi radio yang bersifat pasif [5], serta RFID reader merupakan perpaduan antara embedding antenna Integrated Circuit (IC) dengan perangkat scanner radio [6]

Penggunaan teknologi ini pernah digunakan sebagai sistem pengaman kunci pintu otomatis yang dilengkapi dengan (PIN) Personal Identification Number [7]. Dan penelitian selanjutnya untuk keperluan untuk keperluan rekam medis dengan tampilan smartphone dan menggunakan teknologi RFID sebagai inputnya [8]. Berdasarkan latar belakang itu maka penulis berinovasi membuat sistem keamanan dengan pertimbangan teknologi ini digunakan untuk berbagai keperluan.

Arduino merupakan platform elektronik open source yang berbasis pada perangkat lunak dan perangkat keras papan Arduino dapat membaca masukan dan menyalakan berbagai sensor seperti lampu, sensor suhu dan sebagainya [9].

\section{Metode Penelitian}

Perancangan Immobilizer berbasis RFID menggunakan metode eksperimental dengan melakukan percobaan langsung pada kendaraan bermotor. dalam membuat sistem ini dengan melakukan beberapa tahap yaitu analisis kebutuhan. Perancangan Perangkat. dan pengujian sistem tersebut i. Analisis Kebutuhan. Tahap pertama untuk pembuatan sistem keamanan ini adalah analisis kebutuhan yang diperlukan dalam perancangan immobilizer berbasis RFID meliputi perangkat keras dan perangkat lunak yang akan digunakan

ii. Kebutuhan Perangkat Keras Dalam penelitian ini penulis menggunakan Laptop Asus A4551 intel Core i3 dan kabel Serial COM dalam berkomunikasi dengan mikrokontroler Arduino UNO R3 dan untuk proses input menggunakan modul RFID RC522 dengan spesifikasi frekuensi 13,56 Khz sebagai input untuk menyalakan sepeda motor serta sensor getar SW420 serta, kabel jumper untuk menghubungkan Arduino dengan modul RFID dan papan PCB Printed Cirkuit Board

iii. Kebutuhan Perangkat Lunak Dalam pembuatan immobilizer ini penulis menggunakan software Arduino IDE serta software Fritzing untuk keperluan dalam perancangan desain alat yang akan dibuat dan penggunaan software proteus dalam pembuatan skematik pada PCB.

iv. Perancangan Perangkat Keras perancangan perangkat keras dalam pembuatan sistem ini penulis menggunakan model eksperimental di mana alat tersebut diterapkan pada sepeda motor dan sketsa rangkaian dapat dijelaskan pada gambar 1 dan skematik alat pada gambar 2

v. Perancangan perangkat lunak tahap selanjutnya yaitu perancangan perangkat lunak dimana perancangan pada tahap ini menentukan kinerja dari perangkat keras dimana dijelaskan pada diagram blok sistem pada gambar 3 dan diagram alir pada gambar 4

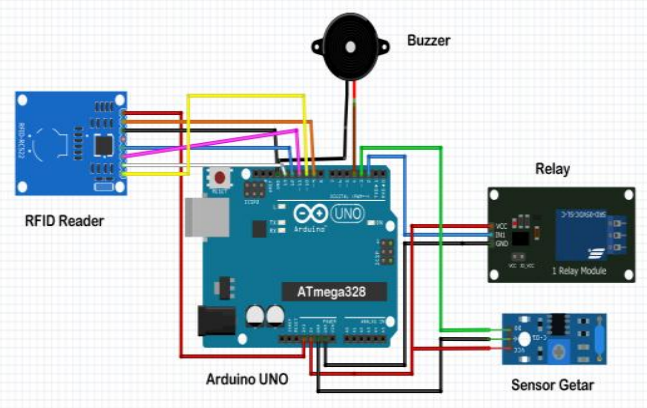

Gambar 1. Sketsa rancangan perangkat keras. 


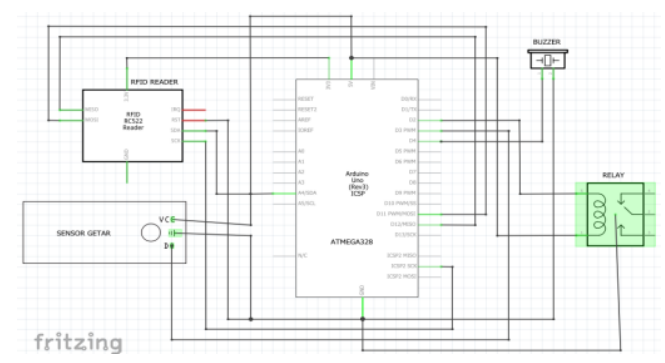

Gambar 2. Skematik rangkaian keseluruhan

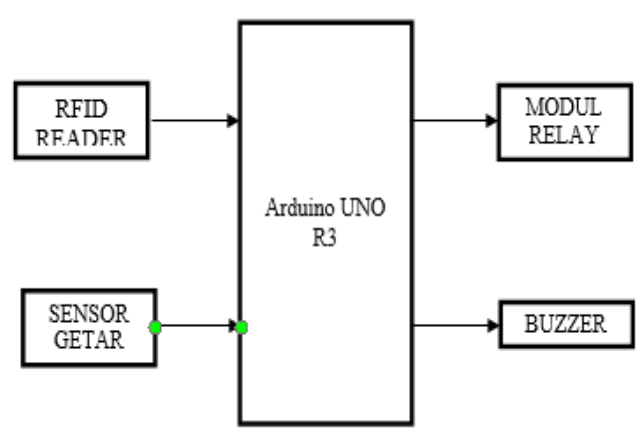

Gambar 3. Skematik rangkaian keseluruhan

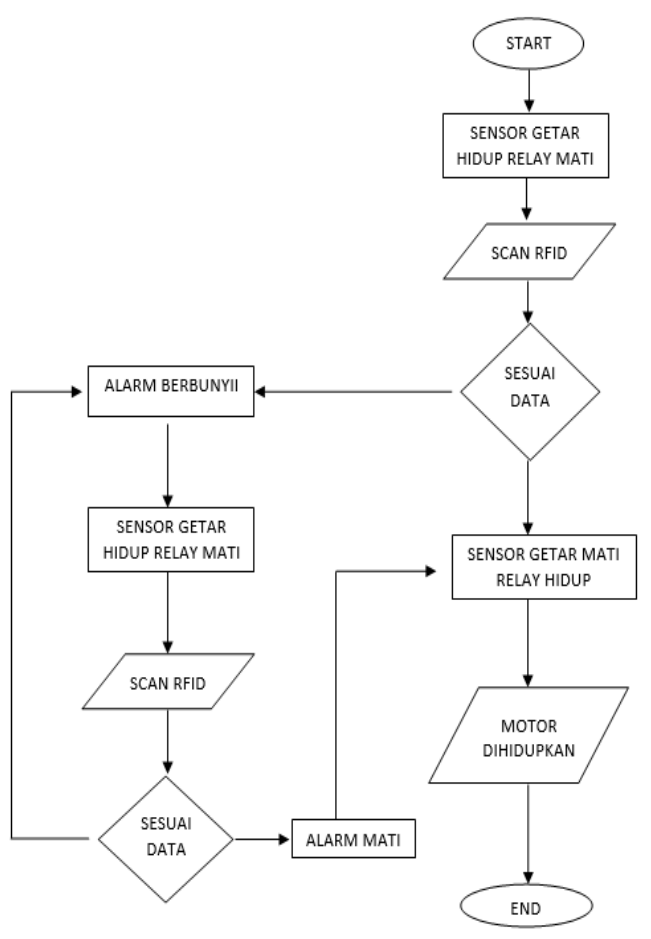

Gambar 4. Diagram alir

Berikut penulisan listing kode program untuk perancangan perangkat lunak dalam membuat sistem keamanan motor berbasis Radio Frequency Identification (RFID) dimana menggunakan bahasa pemrograman arduino yang di tunjukan oleh gambar 5 serta fungsi pembacaan RFID pada gambar 6

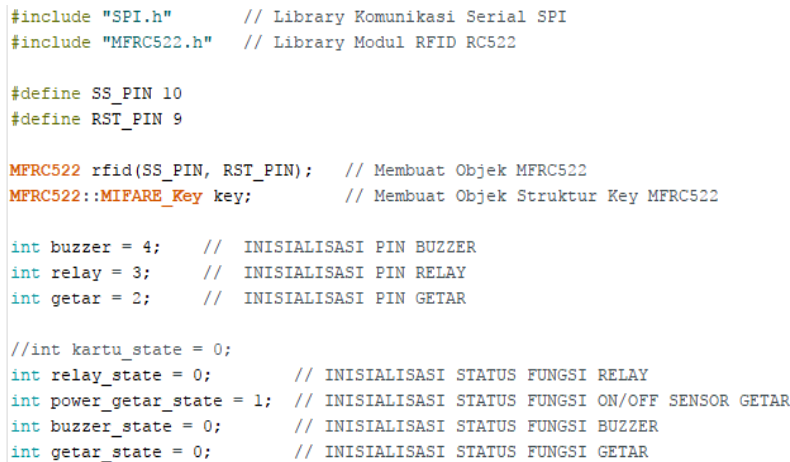

Gambar 5. kode program Inisialisasi Pin yang digunakan

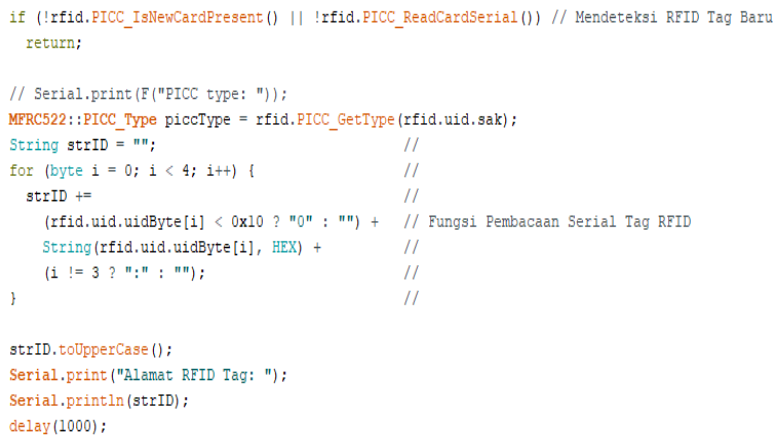

Gambar 6. Fungsi pembacaan ID tag

\section{HASIL DAN PEMBAHASAN}

\section{A. Pemasangan Rangkaian Sistem pada sepeda motor}

Pada (Gbr. 1), dirakit dengan langkah pertama kabel positif pada kontak sepeda motor yang terhubung langsung dengan aki dan koil di putus lalu di sambung dengan kabel tambahan yang kemudian dipasang dengan relay yang dimana relay tersebut di control oleh Arduino yang inputnya berasal dari RFID dan pemasangan sensor getar dipasang pada dipasang pada body motor untuk mendeteksi getaran dari body motor lalu setelah itu buzzer untuk alarm keamanan 


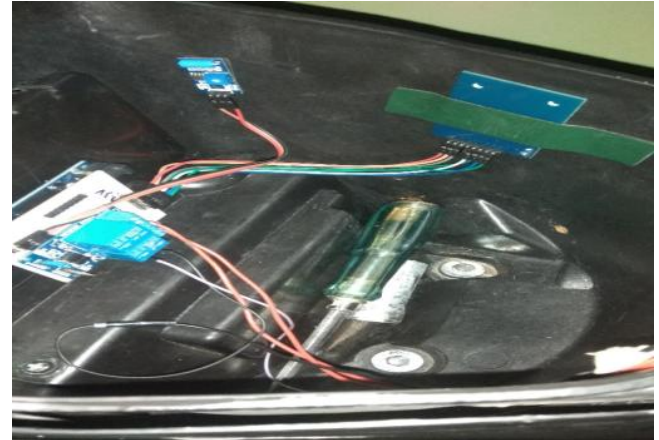

Gambar 1. Rangkaian Sistem Embedded yang dipasang di sepeda motor

B. Pengujian tag RFID dan Jarak jangkauan penggunaan

Pada pengujian ini untuk mengetahui sistem yang dibuat dan jarak efektif yang digunakan RFID membaca ID tag yang ditunjukan pada Tabel 1 dan 2

TABEL I. PENGUJIAN BEBERAPA TAG RFID

\begin{tabular}{|c|c|c|c|}
\hline No & Alamat Tag & $\begin{array}{c}\text { Relay } \\
\text { menyala }\end{array}$ & $\begin{array}{c}\text { Buzzer } \\
\text { menyala }\end{array}$ \\
\hline 1 & 8C:9F:C6:DB & Menyala & Mati \\
\hline 2 & 4A:9F:BB:79 & Mati & Hidup \\
\hline 3 & $33: 5 A: E 4: 2 B$ & Mati & Hidup \\
\hline 4 & C0:B6:13:A3 & Mati & Hidup \\
\hline
\end{tabular}

TABEL II. PERBANDINGAN JARAK KANGKAUAN RFID READER

\begin{tabular}{|l|l|l|l|}
\hline \multirow{2}{*}{ Jarak } & \multicolumn{3}{|c|}{ Jenis Deteksi } \\
\cline { 2 - 4 } & $\begin{array}{l}\text { Tanpa } \\
\text { Halangan }\end{array}$ & Buku & Plastik \\
\hline $0 \mathrm{~cm}$ & Terbaca & Terbaca & Terbaca \\
\hline $1 \mathrm{~cm}$ & Terbaca & Terbaca & Terbaca \\
\hline $2 \mathrm{~cm}$ & Terbaca & Terbaca & Terbaca \\
\hline $3 \mathrm{~cm}$ & Terbaca & Tidak & Tidak \\
Terbaca & Terbaca & Tidak & $\begin{array}{c}\text { Tidak } \\
\text { Terbaca }\end{array}$ \\
\hline $4 \mathrm{~cm}$ & Tidak & Terbaca & Terbaca \\
\hline
\end{tabular}

\section{Pengujian Sistem dangan Berbagai Kondisi}

Pada pengujian ini dimaksudkan untuk melihat sistem dilakukan dengan berbagai kondisi agar sesuai yang diharapkan yang ditunjukan Tabel 3

\section{TABEL III. PENGUJIAN SISTEM DENGAN BERBAGAI KONDISI}

\begin{tabular}{|c|c|c|}
\hline $\mathrm{No}$ & Uraian & Kondisi Motor \\
\hline 1 & $\begin{array}{l}\text { Menyalakan } \\
\text { sepeda motor } \\
\text { dengan } \\
\text { menggunakan } \\
\text { Kunci Motor }\end{array}$ & $\begin{array}{l}\text { Kondisi sepeda } \\
\text { motor Mati karena } \\
\text { sambungan masih } \\
\text { terputus dari relay } \\
\text { yang dikontrol } \\
\text { RFID }\end{array}$ \\
\hline 2 & $\begin{array}{l}\text { Menyalakan } \\
\text { sepeda motor } \\
\text { menggunakan } \\
\text { dengan RFID }\end{array}$ & $\begin{array}{l}\text { Kondisi sepeda } \\
\text { motor Mati karena } \\
\text { tanpa } \\
\text { menggunakan } \\
\text { kunci dalam } \\
\text { menyalakan } \\
\text { motor }\end{array}$ \\
\hline 3 & $\begin{array}{l}\text { Menyalakan } \\
\text { sepeda motor } \\
\text { menggunakan } \\
\text { dengan Kunci } \\
\text { Motor + RFID }\end{array}$ & $\begin{array}{l}\text { Kondisi sepeda } \\
\text { motor hidup } \\
\text { karena pada relay } \\
\text { telah tersambung } \\
\text { dan menggunakan } \\
\text { kunci untuk } \\
\text { menghidupkan }\end{array}$ \\
\hline
\end{tabular}

\section{Pengujian Sistem menggunakan monitor serial}

Pada pengujian ini untuk mengetahui sistem dan alat apakah berjalan sesuai dengan harapan melalui serial monitor yang di tunjukan pada (Gbr 1)

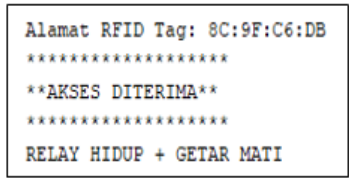

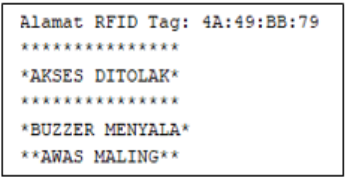

(b)
ADA PERGETARAN!

ANAS MALING 
Gambar 1. tampilan serial monitor (a) alamat sesuai data (b) alamat tidak sesuai data (c) pengujian Sensor getar

\section{KESIMPULAN}

Setelah tahapan penelitian yang dilakukan diadapatkan kesimpulan dengan beberapa hasil yaitu pada penggunaa RFID tag harus dilakukan dengan jarak efektif yaitu $0-2 \mathrm{~cm}$ serta dalam penggunaan sepeda motor harus menggunakan RFID yang telah disetting dan menggunakan kunci konvensional dan apabila pengguna RFID yang tidak disetting maka menghasilkan alarm dan penggunaan sesnor getar sesuai fungsinya sebagai alat keamanan dan buzzer sebagai alarm peringatan

\section{Daftar Pustaka}

[1] Saragih, F. A. (2016, Agustus 20). Anda Tahu Populasi Kendaraan di Indonesia? Retrieved Oktober 19, 2017, from Kompas.com:

http://otomotif.kompas.com/read/2016/08 /20/103100215/Anda.Tahu.Populasi.Ken daraan.di.Indonesia.

[2] Setiawan, E. (2015, April 3). Tiga Bulan, 186 Kasus Curanmor Terjadi di Semarang. Retrieved Oktober 19, 2017, from Sindonews.com: https://daerah.sindonews.com/read/98491 6/22/tiga-bulan-186-kasus-curanmorterjadi-di-semarang-1428071523
[3] Saputra, I. Y. (2017, Agustus 17). Operasi Jaran Candi, Polda Jateng Ungkap 328 Kasus Curanmor. Retrieved Oktober 19, 2017, from Semarangpos.com:http://www.semarangp os.com/2017/08/17/pencurian-semarangoperasi-jaran-candi-polda-jateng-ungkap328-kasus-curanmor-84376

[4] Addepalli,S. L., \& Addepalli, S. G. (2014). Library Management System Using RFID. International Journal of Computer. Science and Information Technologies, 5(6), 6932-6935. [5] Amendola, S. ¿.. Lodato,R .,Manzari,S April). RFID Technology for IoT-Based Personal Healthcare in Smart Spaces. JOURNAL, I(2), 144 - 152.

[6] Annaraman, Thamarai, P., \& Kumar, T. K. (2015). 'Smart Library Management System using RFID. International Journal of Advanced Research in Electrical Electronics and Instrumentation Engineering, 4(4), 19161925

[7] Rerungan, J., Nugraha, D. W., \& Anshori, Y. '(2014). Sistem Pengäman Pintu Otomatis Menggunakan Radio Frequency Identification (RFID) Tag Card Dan Personal Identification Number ATMEGA 128. Jurnal MEKTRIK, 1(1), 20-28

[8] Sunarya, U. Halomoan, J., \& Ruswanda, G. A. (2015). Perancangan Rekam Medis PPTM Berbasis Android \& Mikrokontroler Menggunakan Teknologi RFID. JNTETI, 4(1), 50 -55

[9] Arduino. (2005) Arduino-Introduction. Retrieved Oktober 19, 2017, from Arduino:

https://www.arduino.cc/en/Guide/Introdu ction 